Molecules 2001, 6, 533-539

molecules

ISSN 1420-3049

http://www.mdpi.org

\title{
Synthesis of 5-(4-X-Phenyl)-10,15,20-tris(Substituted Phenyl) Porphyrins Using Dipyrromethanes
}

\section{Edgardo N. Durantini}

Departamento de Química y Física, Universidad Nacional de Río Cuarto, Agencia Postal No 3, Río Cuarto 5800, Argentina; e-mail: edurantini@exa.unrc.edu.ar

Received: 27 November 2000; in revised form 8 May 2001 / Accepted: 9 May 2001 / Published: 31 May 2001

\begin{abstract}
X-Phenyl)-10,15,20-tris(substituted phenyl) porphyrins (4-6) were synthesized from meso-(substituted phenyl) dipyrromethanes (1-3), which in turn were prepared in yields of 75-92 \%. This synthetic pathway was compared with the binary mixed aldehyde and pyrrole condensation method. The reported dipyrromethane approach is advantageous for porphyrins substituted by $-\mathrm{OCH}_{3}$ (4) and $-\mathrm{F}(6)$ groups (12-14 \%), while the yield of porphyrins bearing $-\mathrm{N}\left(\mathrm{CH}_{3}\right)_{2}(5)$ groups was similar $(\sim 0.3 \%)$ by both methods.
\end{abstract}

Keywords: Porphyrin; dipyrromethane.

\section{Introduction}

Meso-substituted porphyrins are the great interest for the development of model systems in biomimetic and materials chemistry [1]. Peripherally asymmetric $\mathrm{AB}_{3}$-porphyrins, bearing three identical substituted phenyl groups (B), can be covalently linked to other structures by the functional group contained in the remaining phenyl substituent (A) [2,3]. These porphyrins bearing two different types of meso-substituents can be prepared by a binary mixed aldehyde condensation [4,5]. However, this 
approach is statistical in nature and usually six porphyrins are formed [6]. Product isolation requires careful and tedious chromatographic separations, the yield is very poor and it is not always possible to isolate pure porphyrin. More direct approaches to trans-substituted porphyrins are provided by condensation of dipyrromethane with aldehyde [7]. This route requires access to meso-substituted dipyrromethane, which can be synthesized from the reaction of aldehyde with excess of pyrrole catalyzed by acid [7,8]. In this paper, 5-(4-X-phenyl)-10,15,20-tris(substituted phenyl) porphyrins (4-6) were synthesized from meso-(substituted phenyl) dipyrromethanes (1-3). The yields obtained using the dipyrromethane approach are considerably higher for porphyrins substituted by $-\mathrm{OCH}_{3}(4)$ and $-\mathrm{F}(6)$ groups than when the binary mixed aldehyde and pyrrole condensation method was used. However, in spite of the fact that dipyrromethane 2 substituted by $-\mathrm{N}\left(\mathrm{CH}_{3}\right)_{2}$ was obtained with appreciable yield, it does not present any advantage, as far as yield is concerned, for the synthesis of porphyrin $\mathbf{5}$.

\section{Results and Discussion}

\section{Dipyrromethane formation.}

The condensation of substituted benzylaldehyde with a large excess of pyrrole (1:45 aldehyde/ pyrrole mol ratio) catalyzed by trifluoroacetic acid affords meso-(4-substituted phenyl) dipyrromethanes 1-3 (Scheme 1). Under these conditions, pyrrole serves both as the reactant in excess and as the solvent for the reaction. Complete consumption of the aldehyde was observed after stirring the mixture for 25 min at room temperature.

\section{Scheme 1}

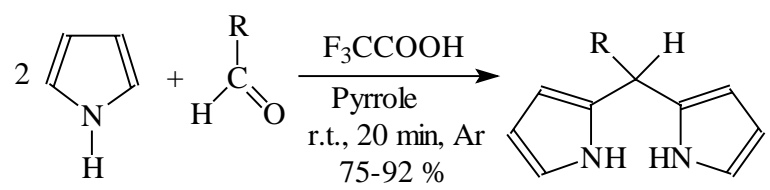

(1) $\mathrm{R}$

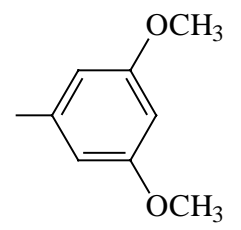

(2) $\mathrm{R}$

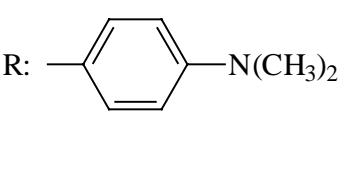

(3) R:

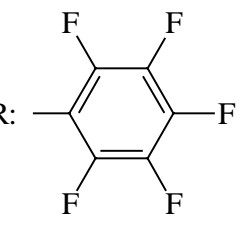

The dipyrromethanes 1, 2 and 3 were isolated by flash chromatography in 87, 75 and $92 \%$ yields, respectively. A mildly basic medium (n-hexane/ethyl acetate/triethylamine $\sim 1 \%$ ) was used as eluant to prevent the decomposition of the dipyrromethane on the silica column used. 
Dipyrromethanes 1-3 are stable in the purified form if stored at $0^{\circ} \mathrm{C}$ under nitrogen atmospheres and in the absence of light. The results show that this condensation reaction is compatible with aromatic aldehydes bearing $-\mathrm{OCH}_{3},-\mathrm{N}\left(\mathrm{CH}_{3}\right)_{2}$ and $-\mathrm{F}$ groups, widening the broad scope of these reactions $[7,8]$.

\section{Synthesis of porphyrins}

Porphyrins 4-6 were synthesized by the acid-catalyzed condensation of dipyrromethanes 1-3 and the corresponding benzaldehyde derivatives in chloroform at room temperature (Scheme 2).

\section{Scheme 2}

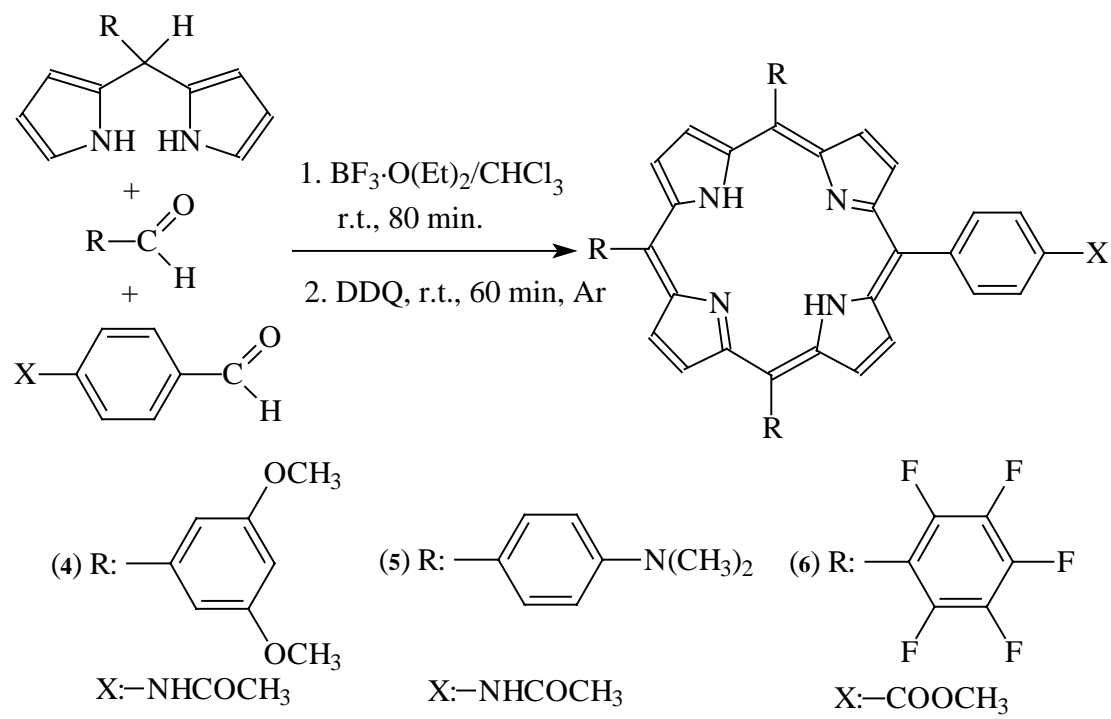

Mixed-benzaldehyde dipyrromethane condensations were performed using about [2.2:1.4:1] molar ratios of dipyrromethane, 4-X-benzaldehyde and substituted benzaldehyde. These amounts of reactants lead to better yields of the selected $\mathrm{AB}_{3}$-porphyrins. Under the experimental conditions used the acidcatalyzed fragmentation of dipyrromethane leads to an increase in the formation of symmetric porphyrins. Consequently, this side reaction was minimized by adding a small excess of the 4-X benzaldehyde with respect to the substituted benzaldehyde. After this adjustment, the reaction mixture was subjected to oxidation with 2,3-dichloro-5,6-dicyano-1,4-benzoquinone (DDQ). The porphyrins were separated in high purity by flash chromatography using dichloromethane/methanol or acetone mixtures as eluants. In all these cases, the first purple band corresponds to the meso-tetra(substituted phenyl) porphyrin and the second is the desired $\mathrm{AB}_{3}$-porphyrins (4-6), which were obtained in yields of $14,0.3$ and $12 \%$, respectively. In each case, the corresponding symmetrical porphyrins were formed in yields of $12,0.5$ and $10 \%$, respectively.

Another way of preparing these porphyrins, bearing two different types of meso-substituents, is a binary mixed aldehyde condensation. Thus, porphyrin $\mathbf{4}$ was synthesized using this procedure by heating 
a mixture of 4-acetamidobenzaldehyde, 3,5-methoxybenzaldehyde and pyrrole in propionic acid at $90{ }^{\circ} \mathrm{C}$ for $1 \mathrm{~h}$. The reaction workup was not simple due to the difficulty of removing the propionic acid and the tars present. Porphyrin 4 was separated by slow column chromatography to yield $2.6 \%$ of the desired compound. Porphyrin 5 was also prepared under similar conditions using a mixture of 4acetamidobenzaldehyde, 4-N,N-dimethylaminobenzaldehyde and pyrrole yielding the desired product in a yield of $\sim 0.4 \%$ after a lenghty purification procedure [4]. The synthesis of porphyrin 6 via a modification of Lindsay's method was previously reported in the literature [5]. The reaction of pentafluorbenzaldehyde, 4-carbomethoxybenzaldehyde and pyrrole was performed in chloroform using trifluoracetic acid as catalyst to yield $\sim 1.5 \%$ of porphyrin 6 .

In conclusion, the reported results expand the scope of the $\mathrm{AB}_{3}$-porphyrin synthesis using dipyrromethane/benzaldehyde mixtures [8]. This method considerably increases the yields of porphyrins 4 and 6 in comparison with the binary mixed aldehyde condensation procedures. However, this pathway does not present any advantage in the synthesis of porphyrin $\mathbf{5}$, substituted by $-\mathrm{N}\left(\mathrm{CH}_{3}\right)_{2}$ groups. In this case, the presence of a high level of side products was detected. The amine group apparently produces an increase in the formation of open-chain oligomers, which complicate the porphyrin purification and the yield is considerably diminished. Trifluoroacetic acid, an alternative catalyst of these reactions instead of $\mathrm{BF}_{3} \mathrm{O}(\mathrm{Et})_{2}$, could diminish the acidolysis of 1,9-unsubstituted dipyrromethanes and the amount of oligomers formed [9]. Finally, the resulting amido porphyrins 4-6 can be hydrolyzed to the correponding amino porphyrins, which are interesting starting materials for preparing supramolecules linked by amide bond [1].

\section{Acknowledgments}

The author is grateful to the Consejo Nacional de Investigaciones Científicas y Técnicas (CONICET), Fundación Antorchas and Agencia Nacional de Promoción Científica y Tecnológica of Argentina for financial support. E.N.D. is a scientific member of CONICET.

\section{Experimental}

\section{General}

Absorption spectra were recorded on a Shimadzu UV-2401PC. NMR spectra were recorded on a Varian Gemini spectrometer at $300 \mathrm{MHz}$. Mass spectra were taken with a Varian Matt 312 operating in EI mode at $70 \mathrm{eV}$. All the chemicals were received from Aldrich and were used without further purification. Solvents (Merck, GR grade) were redistilled. Chloroform was stored over $4 \AA$ molecular sieves. 


\section{Synthesis of dipyrromethane derivative.s}

meso-(3,5-Dimethoxyphenyl)dipyrromethane (1).- A solution of 3,5-dimethoxybenzaldehyde (1.33 g, 8 mmol) and pyrrole $(25 \mathrm{~mL} 360 \mathrm{mmol})$ was degassed by bubbling with argon for $15 \mathrm{~min}$, then trifluoroacetic acid (154 $\mu \mathrm{L}, 2 \mathrm{mmol})$ was added. The solution was stirred for $25 \mathrm{~min}$ at room temperature, at which point no starting aldehyde was evident by TLC analysis (cyclohexane/ethyl acetate/triethylamine; 80:20:1). The mixture was diluted with dichloromethane $(50 \mathrm{~mL})$, washed with aqueous $0.1 \mathrm{M} \mathrm{NaOH}(50 \mathrm{~mL})$ and then washed with water. The organic phase was dried with $\mathrm{Na}_{2} \mathrm{SO}_{4}$, filtered and the solvent was removed under reduced pressure. The unreacted pyrrole was removed by vacuum distillation at room temperature. Flash chromatography (silica gel, cyclohexane/ ethyl acetate/triethylamine; 80:20:1) yielded $1.96 \mathrm{~g}$ (87\%) of the pure dipyrromethane 1 . TLC (silica gel) $\mathrm{R}_{\mathrm{f}}$ (cyclohexane/ethyl acetate/triethylamine 80:20:1) =0.40. ${ }^{1} \mathrm{H}-\mathrm{NMR}\left(\mathrm{CDCl}_{3}, \mathrm{TMS}\right) \delta[\mathrm{ppm}] 3.85(\mathrm{~s}, 6 \mathrm{H})$; $5.41(\mathrm{~s}, 1 \mathrm{H}$, meso-H); 5.90 (m, 2H, pyrrole-H); 6.15 (q, 2H, pyrrole-H); 6.69 (m, 2H, pyrrole-H); 6.87 (t, $1 \mathrm{H}, \mathrm{J}=2.4 \mathrm{~Hz}) ; 7.38$ (t, 2H, J=2.4 Hz); 7.92 (s, brs, 2H, pyrrole-NH). MS [m/z] $282\left(\mathrm{M}^{+}\right)$. Anal. Calcd. for $\mathrm{C}_{17} \mathrm{H}_{18} \mathrm{~N}_{2} \mathrm{O}_{2}$ : C 72.32, H 6.42, N 9.92; found C 72.27, H 6.46, N 9.98.

meso-(4-N,N-Dimethylaminophenyl)dipyrromethane (2)-. A sample of 4-N,N-dimethylamino benzaldehyde (1.19 g, $8 \mathrm{mmol}$ ) was processed as described for dipyrromethane 1, affording $1.60 \mathrm{~g}$ (75 $\%$ ) of the pure dipyrromethane 2 . TLC (silica gel) $\mathrm{R}_{\mathrm{f}}$ (cyclohexane/ethyl acetate/triethylamine 80:20:1) = 0.26. ${ }^{1} \mathrm{H}-\mathrm{NMR}\left(\mathrm{CDCl}_{3}\right.$, TMS) $\delta[\mathrm{ppm}] 2.90(\mathrm{~s}, 6 \mathrm{H}) ; 5.35(\mathrm{~s}, 1 \mathrm{H}$, meso-H); 5.91 (m, 2H, pyrrole-H); 6.12 (q, 2H, pyrrole-H); 6.66 (m, 2H, pyrrole-H); 7.06 (d, 2H, J=8.5Hz); 7.41 (d, 2H, J=8.7Hz); 7.97 (s, brs, $2 \mathrm{H}$, pyrrole-NH). MS [m/z] $265\left(\mathrm{M}^{+}\right)$. Anal. Calcd. for $\mathrm{C}_{17} \mathrm{H}_{19} \mathrm{~N}_{3}$ : C 76.95, H 7.22, N 15.84; found C 76.89, H 7.28, N 15.88 .

meso-(Pentafluorophenyl)dipyrromethane (3).- A sample of pentafluorobenzaldehyde (1.57 g, $8 \mathrm{mmol})$ was processed as described for dipyrromethane 1, affording $2.30 \mathrm{~g}(92 \%)$ of the pure dipyrromethane 3 . TLC (silica gel) $\mathrm{R}_{\mathrm{f}}$ (cyclohexane/ethyl acetate/triethylamine 80:20:1) $=0.46 .{ }^{1} \mathrm{H}-\mathrm{NMR}\left(\mathrm{CDCl}_{3}, \mathrm{TMS}\right) \delta$ 5.88 (s, 1H, meso-H); 6.00 (m, 2H, pyrrole-H); 6.15 (q, 2H, pyrrole-H); 6.74 (m, 2H, pyrrole-H); 8.10 (s, brs, $2 \mathrm{H}$, pyrrole-NH). MS [m/z] $312\left(\mathrm{M}^{+}\right)$. Anal. Calcd. for $\mathrm{C}_{15} \mathrm{H}_{9} \mathrm{~N}_{2} \mathrm{~F}_{5}$ : C 57.70, H 2.91, N 8.97; found C 57.79 H 2.83, N 8.90.

\section{Synthesis of meso-substituted porphyrins}

5-(4-Acetaminophenyl)-10,15,20-tris(3,5-dimethoxyphenyl) porphyrin (4).- A solution of 3,5dimethylbenzaldehyde $(257 \mu \mathrm{L}, 1.55 \mathrm{mmol})$, 4-acetamidobenzaldehyde (350 $\mathrm{mg}, 2.15 \mathrm{mmol})$ and dipyrromethane 1 (974 mg, $3.45 \mathrm{mmol}$ ) in $250 \mathrm{~mL}$ of chloroform was purged with argon for $15 \mathrm{~min}$. Then $\mathrm{BF}_{3} \mathrm{O}(\mathrm{Et})_{2}$ (1.05 mmol, $0.42 \mathrm{~mL}$ of $2.5 \mathrm{M}$ stock solution in chloroform) was added. The solution 
was stirred for $80 \mathrm{~min}$ at room temperature. Then, DDQ (510 $\mathrm{mg}, 2.25 \mathrm{mmol}$ ) was added and the mixture was stirred for an additional $1 \mathrm{~h}$ at room temperature. The solvent was removed under reduced pressure and flash column chromatography (silica gel, dichloromethane/acetone $5 \%$ ) gives $185 \mathrm{mg}(14 \%)$ of the pure desired porphyrin 5 as the second moving band. TLC (silica gel) $\mathrm{R}_{\mathrm{f}}$ (dichloromethane/acetone 5\%) $=0.33$. UV-visible $\lambda_{\max }$ (dichloromethane) $[\mathrm{nm}]\left(\varepsilon\left[\mathrm{M}^{-1} \mathrm{~cm}^{-1}\right]\right) 422(475,000), 516(20,900), 551(7,500)$, $592(6,300)$ and 650 (3,800). ${ }^{1} \mathrm{H}-\mathrm{NMR}\left(\mathrm{CDCl}_{3}\right.$, TMS) $\delta-2.79(\mathrm{~s}, 2 \mathrm{H}$, brs, pyrrole N-H); $3.96(\mathrm{~s}, 18 \mathrm{H}, \mathrm{Ar}-$ $\left.\mathrm{OCH}_{3}\right) ; 6.89$ (t, 3H, J=2.4Hz,10,15,20-Ar); 7.39 (t, 6H, J=2.4Hz, 10,15,20-Ar); 7.48 (brs, 1H, Ar$\mathrm{NHCO}$ ); 7.87 (d, 2H, J=8.0Hz, 5-Ar); 8.17 (d, 2H, J=8.0Hz, 5-Ar); 8.90-8.95 (m, 8H, pyrrole-H). MS [m/z] $851\left(\mathrm{M}^{+}\right)$. Anal. Calcd. for $\mathrm{C}_{52} \mathrm{H}_{45} \mathrm{~N}_{5} \mathrm{O}_{7}$ : C 73.31, H 5.32, N 8.22; found C 73.40, H 5.39, N 8.15.

Porphyrin 4 was also synthesized from a mixture of 3,5-dimethoxylbenzaldehyde $(1.5 \mathrm{~g}, 9 \mathrm{mmol})$ and 4-acetamidobenzaldehyde $(490 \mathrm{mg}, 3 \mathrm{mmol})$ in propionic acid $(100 \mathrm{~mL})$ stirred at $90{ }^{\circ} \mathrm{C}$. Then, $1.1 \mathrm{~mL}$ of pyrrole $(16 \mathrm{mmol})$ was slowly added. The resulting mixture was allowed to reflux for one hour at which time it was poured into $350 \mathrm{~mL}$ of water (containing $10 \mathrm{~g}$ of $\mathrm{NaCl}$ ). The precipitated material (green mass) was collected by vacuum filtration. The precipitate was dried under vacuum at $60{ }^{\circ} \mathrm{C}$ for 48 hours to remove propionic acid. The resulting material was dissolved in chloroform/ methanol (5\%) and filtered on short column of alumina. This procedure was repeated using silica gel. The solvents were removed under reduced pressure and treated with DDQ (908 mg, $4 \mathrm{mmol}$ ) in $150 \mathrm{~mL}$ of chloroform for 2 hours. The solvent was evaporated and the residual was pulverized to a fine powder. Slow chromatography column (silica gel, chloroform/methanol gradient) afforded $66 \mathrm{mg}(2.6 \%)$ of the pure desired porphyrin $\mathbf{4}$ as the second moving band.

5-(4-Acetaminophenyl)-10,15,20-tris(4-N,N-dimethylaminophenyl) porphyrin (5).- A sample of 4-N,Ndimethylaminobenzaldehyde (231 mg, $1.55 \mathrm{mmol})$, 4-acetamidobenzaldehyde (350 mg, $2.15 \mathrm{mmol}$ ) and dipyrromethane 2 (914 $\mathrm{mg}, 3.45 \mathrm{mmol})$ was processed as described for porphyrin 4 . The solution was treated water $(100 \mathrm{~mL})$ and the organic phase was extracted with dichloromethane. The solvent was removed under reduced pressure. The residue was purified by flash chromatography (dichloromethane/methanol 1\%). This procedure was repeated to yield $4 \mathrm{mg}(0.3 \%)$ of the pure selected porphyrin 5 as second moving band. TLC (silica gel) $\mathrm{R}_{\mathrm{f}}$ (dichloromethane/ methanol 3\%) $=0.46$. MS $[\mathrm{m} / \mathrm{z}] 800\left(\mathrm{M}^{+}\right)$. Spectroscopic data for porphyrin $\mathbf{5}$ were previously reported [4].

5-(4-Carbomethoxyphenyl)-10,15,20-tris(pentafluorophenyl) porphyrin (6).- A sample of pentafluorobenzaldehyde (353 mg, $1.8 \mathrm{mmol})$, 4-carboxymethylbenzaldehyde (410 mg, $2.5 \mathrm{mmol})$ and dipyrromethane 3 (1.25 g, $4.0 \mathrm{mmol}$ ) was processed as described for porphyrin 4. Purification by flash chromatography afforded $203 \mathrm{mg}(12 \%)$ of the pure porphyrin $\mathbf{6}$ as the second moving band. TLC (silica gel) $\mathrm{R}_{\mathrm{f}}$ (dichloromethane) $=0.61$. MS $[\mathrm{m} / \mathrm{z}] 942\left(\mathrm{M}^{+}\right)$. Spectroscopic data for porphyrin 6 were identical to those previously reported [5]. 


\section{References}

1. (a) Wasielewki, M. R. Photoinduced electron transfer in supramolecular systems for artificial photosynthesis. Chem. Rev. 1992, 92, 435-461. (b) Gust, D.; Moore, T. A.; Moore, A. L. Molecular mimicry of photosynthetic energy and electron transfer. Acc. Chem. Res. 1993, 26, 198-205.

2. Fungo, F.; Otero, L. A.; Sereno, L.; Silber, J. J.; Durantini E. N. Synthesis of porphyrin dyads with potential use in solar energy conversion. J. Mater. Chem. 2000, 10, 645-650.

3. Durantini, E. N. Synthesis of meso-nitrophenyl porphyrins covalently linked to a polyphenylene chain bearing methoxy groups. J. Porphyrins Phthalocyanines 2000, 4, 233-242.

4. Gust, D.; Moore, T. A.; Moore, A. L.; Leggett, L.; Lin, S.; DeGraziano, J. M.; Hermant, R. M.; Nicodem, D.; Craig, P.; Seely, G. R.; Nieman, R. A. Photoinduced electron transfer in a porphyrin dyad. J. Phys. Chem. 1993, 97, 7926-7931.

5. Gust, D.; Moore, T. A.; Moore, A. L.; Gao, F.; Luttrull, D.; DeGraziano, J. M.; Ma, X. C.; Makings, L. R.; Lee, S-J.; Trier, T. T.; Bittersmann, E.; Seely, G. R.; Woodward, S.; Bensasson, R. V.; Rougée, M.; De Schryver, F. C.; Van der Auweraer, M. Long-lived photoinitiated charge separation in carotene-diporphyrin triad molecules. J. Am. Chem. Soc. 1991, 113, 3638-3649.

6. Lindsey, S. J.; Schreiman, Y. C.; Hsu, H. C.; Kearney, P. C.; Marguerettaz, A. M. Rothemund and Adler-Longo reactions revisited: synthesis of tetraphenylporphyrins under equilibrium condituions. $J$. Org. Chem. 1987, 52, 827-836.

7. Lee C-H.; Lindsey, J. S. One-flask synthesis of meso-substituted dipyrromethanes and their application in the synthesis of trans-substituted porphyrin building blocks. Tetrahedron 1994, 50, 11427-11440.

8. Durantini, E. N.; Silber J. J. Synthesis of 5-(4-acetamidophenyl)-10,15,20-tris(4-substituted phenyl) porphyrins using dipyrromethanes. Synth. Commun. 1999, 29, 3353-3368.

9. Lee C-H.; Li F. Iwamoto K.; Dadok J.; Bothner-By A. A.; Lindsey J. S. Synthetic approaches to regioisomerically pure porphyrins bearing four different meso-substituteds. Tetrahedron 1995, 51, 11645-11672.

Sample Availability: Samples are available from the author.

(C) 2001 by MDPI (http://www.mdpi.org). Reproduction is permitted for noncommercial purposes 